\title{
Pengaruh Disiplin Kerja, Pelatihan Kerja dan Kepuasan Kerja terhadap Prestasi Kerja Karyawan PT Angkasa Tour Medan
}

\author{
Manajemen SDM \\ Hendra Nazmi $^{1)}$, Ivannie Angel Gunawan ${ }^{2)}$, Cindy ${ }^{3 *}$ \\ Program Studi Manajemen, Universitas Prima Indonesia \\ *Email: cindytjandra1998@gmail.com
}

\begin{abstract}
Abstrak
Tujuan dari penelitian ini adalah untuk mengetahui dan menganalisa pengaruh disiplin kerja, pelatihan kerja dan kepuasan kerja terhadap prestasi kerja karyawan PT Angkasa Tour Medan. Terjadinya penurunan prestasi kerja karyawan disebabkan disiplin kerja, pelatihan kerja dan kepuasan kerja.Metode penelitian mengunakan kuantitatif. Populasi adalah berjumlah 74 karyawan dan sampel berjumlah 74 karyawan Teknik sampling yang digunakan adalah sampline jenuh. Hasil perhitungan pengujian hipotesis secara parsial disiplin kerja berpengaruh positif dan signifikan terhadap prestasi kerja karyawan PT Angkasa Tour Medan, secara parsial pelatihan kerja berpengaruh positif dan signifikan terhadap prestasi kerja karyawan PT Angkasa Tour Medan, secara parsial kepuasan kerja berpengaruh positif dan signifikan terhadap prestasi kerja karyawan PT Angkasa Tour Medan dan secara simultan Disiplin kerja, pelatihan kerja dan kepuasan kerja berpengaruh positif dan signifikan terhadap prestasi kerja karyawan PT Angkasa Tour Medan.
\end{abstract}

\section{Kata Kunci: Disiplin Kerja, Pelatihan Kerja, Kepuasan Kerja, Kinerja Karyawan}

\section{Abstract}

The purpose of this study was to determine and analyze the effect of work discipline, job training and job satisfaction on employee work performance of PT Angkasa Tour Medan. The decline in employee work performance is due to work discipline, job training and job satisfaction. The research method uses quantitative. The population is 74 employees and the sample is 74 employees. The sampling technique used is saturated sampline. The results of the calculation of the partial hypothesis testing, work discipline has a positive and significant effect on the work performance of PT Angkasa Tour Medan employees, partially job training has a positive and significant effect on the work performance of employees of PT Angkasa Tour Medan, partially job satisfaction has a positive and significant effect on employee work performance. PT Angkasa Tour Medan and simultaneously work discipline, job training and job satisfaction have a positive and significant effect on the work performance of employees of PT Angkasa Tour Medan.

Keywords: Work Discipline, Job Training, Job Satisfaction, Employee Performance 


\section{PENDAHULUAN}

\section{Latar Belakang Masalah}

PT Angkasa Tour Medan merupakan sebuah perusahaan tour and travel. Prestasi kerja karyawan merupakan hal yang sangat penting dalam perusahaan untuk mencapai tujuannya, sehingga perusahaan melakukan berbagai usaha untuk meningkatkannya. Prestasi kerja karyawan pada perusahaan PT Angkasa Tour Medan mengalami penurunan yang terlihat dari banyaknya karyawan yang belum inisiatif dalam bekerja dengan cepat dan tepat dan semangat kerja karyawan mengalami penurunan sehingga mengakibatkan tidak tercapainya target perusahaan PT Angkasa Tour Medan.

Disiplin kerja yang dimiliki oleh karyawan sangat penting bagi suatu perusahaan dalam rangka mewujudkan tujuan perusahaan. Tanpa disiplin kerja karyawan yang baik sulit bagi suatu perusahaan mencapai hasil yang optimal. Disiplin kerja karyawan pada perusahaan PT Angkasa Tour Medan masih rendah tercermin dari terjadinya keterlambatan karyawan dan ketidakahdiran karyawan yang masih tinggi serta banyak karyawan yang tidak mematuhi aturan perusahaan.

Pelatihan kerja berperan penting dalam peningkatan prestasi kerja karyawan. Pelatihan kerja yang diterapkan dalam perusahaan ini masih belum optimal dan efektif sehingga masih belum berdampak pada peningkatan prestasi kerja karyawan. Bahan pelatihan yang diberikan masih sulit untuk mendukung tugas karyawan serta pelatih hanya dari senior atau karyawan yang mempunyai masa kerja yang cukup lama sehingga kurang optimal dalam pemberian pembelajaran kepada karyawan.

Tingkatirasaipuasiindividuibahwaimerekaimendapatiimbalaniyangisetimpalidariiberm acam-macam aspek situasi pekerjaan dari organisasi tempat mereka bekerja. Kepuasan kerja karyawan masih rendah terlihat dari seringnya karyawan tidak optimal dalam bekerja.

\section{Hipotesis Penelitian}

Hipotesis dari penelitian ini yaitu :

$\mathrm{H}_{1}$ : Disiplin kerja berpengaruh secara parsial terhadap prestasi kerja karyawan PT Angkasa Tour Medan

$\mathrm{H}_{2}$ : Pelatihan kerja berpengaruh secara parsial terhadap prestasi kerja karyawan PT Angkasa Tour Medan

$\mathrm{H}_{3}$ : Kepuasan kerja berpengaruh secara parsial terhadap prestasi kerja karyawan PT Angkasa Tour Medan 
$\mathrm{H}_{4}$ : Disiplin kerja, pelatihan kerja dan kepuasan kerja berpengaruh secara simultan terhadap prestasi kerja karyawan PT Angkasa Tour Medan

\section{METODOLOGI PENELITIAN}

Penelitian ini dilakukan pada PT Angkasa Tour Medan yang beralamat di Jalan Wahidin No. Mor 65A Medan. Waktu penelitian dimulai sejak bulan November 2019 dan direncanakan akan selesai pada bulan April 2021. Peneliti mengambil populasi dalam penelitian ini sebanyak 61 karyawan. Jumlah sampel dalam penelitian ini adalah sebanyak 61 responden dan 30 responden untuk perngujian validitas dan reliabilitas yang di ambil dar luar sampel penelitian PT Permata Holiday.

\section{Teknik Pengumpulan Data}

Dalam penelitian ini, pengumpulan data terkait permasalahan yang diteliti oleh peneliti dilakukan dengan cara:

1. Kuesioner, dibagi kepada semua karyawan pada perusahaan.

2. Wawancara, dilakukan kepada karyawan pada perusahaan.

3. Studi dokumentasi, yang digunakan adalah buku-buku, jurnal dan profil perusahaan.

\section{Jenis dan Sumber Data}

Sumber data penelitian terdiri atas:

1. Sumber data primer, meliputi hasil pengisian kuesioner di wawancara. Data primer dalam penelitian ini meliputi hasil pengisian kuesioner dan wawancara

2. Sumber data sekunder, meliputi profil perusahaan, struktur organisasi dan data yang diperoleh dari buku, teori-teori dan data yang berhubungan dengan masalah yang diteliti.

\section{Identifikasi dan Definisi Operasional Variabel Penelitian}

Definisi operasional untuk masing-masing variabel bebas dan variabel terikat adalah sebagai berikut: 
Tabel 1. Definisi Operasional dan Pengukuran Variabel

\begin{tabular}{|c|c|c|c|}
\hline Variabel & Definisi & Indilisator & Slsala Pengulura \\
\hline $\begin{array}{c}\text { Disiplin Kerja } \\
\left(\mathrm{X}_{1}\right)\end{array}$ & $\begin{array}{l}\text { Tindakan manajemen untul mendorong para } \\
\text { angavota ofganisasi memnuhi tuntutan } \\
\text { berbagai ketentuan tersebut. } \\
\text { Sumber : Siagian (2013:305) }\end{array}$ & $\begin{array}{l}\text { 1. Teladan pemimpin } \\
\text { 2. Keadilan } \\
\text { 3. Waskat } \\
\text { 4. Sanksi hukuman } \\
\text { 5. Ketegasan } \\
\text { Sumber: Hasibuan }(2016: 194)\end{array}$ & Stala Lìnert \\
\hline Pelatihan $\left(\mathrm{X}_{2}\right)$ & $\begin{array}{l}\text { Sebuah upaya yang sistematis dan terencana } \\
\text { untuk mengubah atau mengambangtan } \\
\text { pengetahuan, keterampilan, sikap baru yang } \\
\text { sesuai dengan kebutuhan organisasi. } \\
\text { Sumber : Priansa (2014:176) }\end{array}$ & 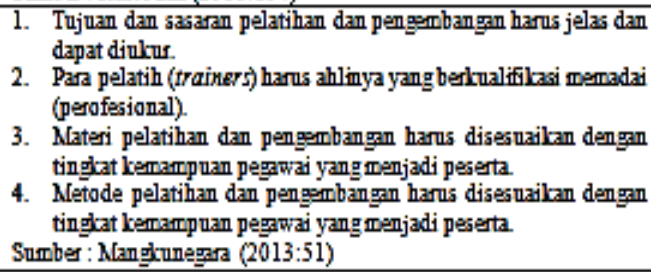 & Stala Likert \\
\hline $\begin{array}{c}\text { Kepuasan Kerja } \\
\left(\mathrm{X}_{j}\right)\end{array}$ & $\begin{array}{l}\text { Sikap atau perasaan kayawan terhadap } \\
\text { aspek-aspek yang menyenangkan atau tidak } \\
\text { menyenangian mengenai pekejeraan yang } \\
\text { sesuai dengan penilaian masing-masing } \\
\text { pekerja. } \\
\text { Surber : Badriyah }(2015: 229)\end{array}$ & $\begin{array}{l}\text { 1. Nenyenagi Pelerjaan } \\
\text { 2. Mencintai pekerjaan } \\
\text { 3. Morai kerja yang positif } \\
\text { 4. Disipin Kerja } \\
\text { 5. Prestari Kerja } \\
\text { Sumber: Tegr (2019:67) }\end{array}$ & Stala Lijkert \\
\hline $\begin{array}{l}\text { Prestasi Kerja } \\
\text { Karyawan } \\
\text { (Y) }\end{array}$ & $\begin{array}{l}\text { Prestasi kerja adalah suatu hasil kerja yang } \\
\text { dicapai seseorang dalam molabsanalan } \\
\text { tugg-tugas yang dibebankan kepadanya } \\
\text { yang didasarkan atas kecakapan. } \\
\text { pengalaman, dan kesungruhan serta waktu. } \\
\text { Sumber: Hasibuan (2016:94) }\end{array}$ & $\begin{array}{l}\text { 1. Hasil kerja } \\
\text { 2. Pengatahuan pelerjaan } \\
\text { 3. Inisiatif } \\
\text { 4. Kecerdasan mental } \\
\text { 5. Sikap } \\
\text { Sumber : Sutrisno (2016:152-153) }\end{array}$ & Stala Lifrert \\
\hline
\end{tabular}

\section{HASIL PENELITIAN}

\section{Uji Asumsi Klasik}

\section{Uji Normalitas}

Dalam menunjukkan terjadinya atau tidak terjadinya normalitas yaitu:

1. Uji grafik.

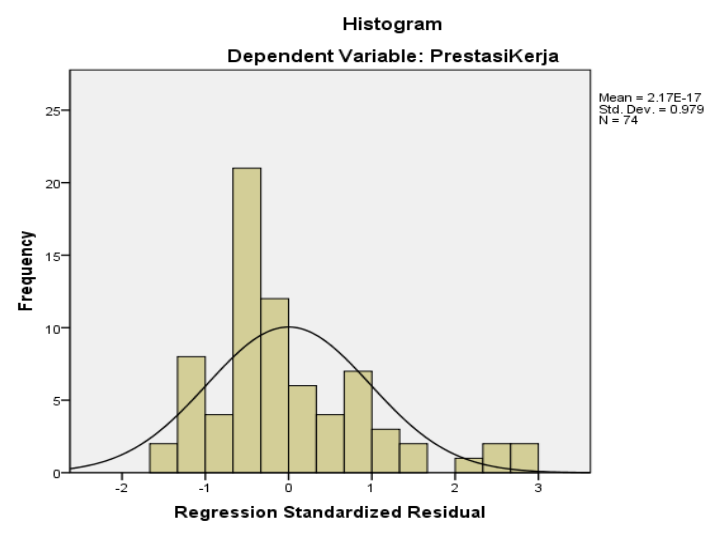

\section{Gambar 1. Uji Normalitas Histogram}

Sumber : Hasil Penelitian, 2020 (Data diolah)

Grafik histogram menunjukkan data riil membentuk garis kurva cenderung simetri (U) tidak melenceng ke kiri atau pun ke kanan maka dapat dikatakan data berdistribusi normal. 


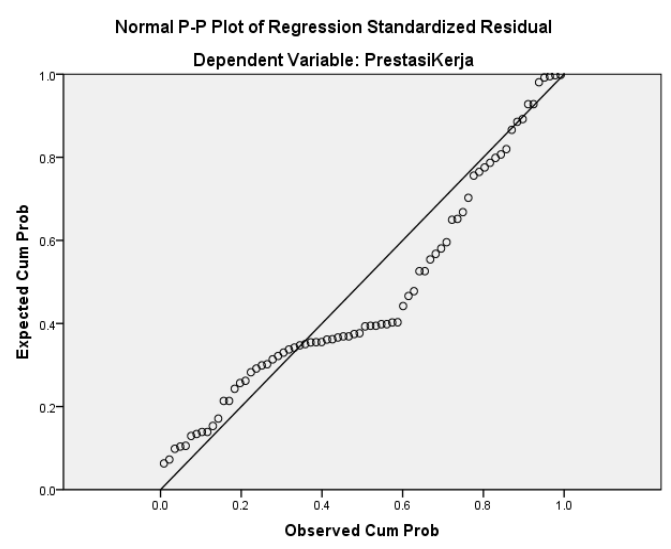

\section{Gambar 2. Uji Normalitas P-P Plot}

Sumber : Hasil Penelitian, 2020 (Data diolah)

Gambar 2. Grafik Normalitas P-P Plot terlihat data menyebar disekitar garis diagonal, penyebarannya sebagian besar mendekati garis diagonal. Hal ini berarti bahwa data berdistribusi normal.

1. Uji statistik

Uji normalitas dengan statistic dapat menggunakan uji statistic non-parametik Kolmogorov-smirnov (K-S), kriteria pengujiannya adalah :

2. Jika nilai signifikansi $>0,05$, maka data berdistribusi normal

3. Jika nilai signifikansi $<0,05$, maka data tidak berdistribusi normal

Berikut ini adalah uji normalitas secara statistik menggunakan Kolmogorov Smirnov.

Tabel 2. Uji Normalitas Kolmogorov Smirnov One-Sample Kolmogorov-Smirnov Test

\begin{tabular}{|c|c|c|}
\hline & & Unstandardized Residual \\
\hline \multicolumn{2}{|l|}{$\mathrm{N}$} & 63 \\
\hline \multirow[t]{2}{*}{ Normal Parameters } & Mean & .0000000 \\
\hline & Std. Deviation & 10.49496393 \\
\hline \multirow[t]{3}{*}{ Most Extreme Differences } & Absolute & .135 \\
\hline & Positive & .135 \\
\hline & Negative & -.068 \\
\hline \multirow{2}{*}{\multicolumn{2}{|c|}{$\begin{array}{l}\text { Kolmogorov-SmirnovZ } \\
\text { Asymp. Sig. (2-tailed) }\end{array}$}} & 1.071 \\
\hline & & .201 \\
\hline
\end{tabular}

Sumber : Hasil Penelitian, 2020 (Data diolah)

Nilai signifikan 0,201>0,05. Dengan demikian dari hasil uji Kolmogorov Smirnov menunjukkan data berdistribusi normal. 


\section{Uji Multikolinearitas}

Hasil pengujian multikolinearitas yaitu:

Tabel 3. Uji Multikolinearitas

\begin{tabular}{|c|c|c|c|c|c|c|c|c|}
\hline \multicolumn{9}{|c|}{ Coefficients ${ }^{\mathrm{a}}$} \\
\hline \multirow{2}{*}{\multicolumn{2}{|c|}{ Model }} & \multicolumn{2}{|c|}{$\begin{array}{l}\text { Unstandardized } \\
\text { Coefficients }\end{array}$} & \multirow{2}{*}{$\begin{array}{c}\begin{array}{c}\text { Standardized } \\
\text { Coefficients }\end{array} \\
\text { Beta } \\
\end{array}$} & \multirow[b]{2}{*}{$t$} & \multirow[b]{2}{*}{ Sig. } & \multicolumn{2}{|c|}{ Collinearity Statistics } \\
\hline & & $B$ & Std. Error & & & & Tolerance & VIF \\
\hline \multirow[t]{4}{*}{1} & (Constant) & .011 & 4.485 & & .002 & .998 & & \\
\hline & Disiplin & .215 & .105 & .229 & 2.056 & .044 & .893 & 1.120 \\
\hline & Pelatihan & .309 & .126 & .278 & 2.457 & .017 & .867 & 1.153 \\
\hline & Kepuasan & .320 & .122 & .299 & 2.624 & .011 & .856 & 1.168 \\
\hline
\end{tabular}

Sumber : Hasil Penelitian, 2020 (Data diolah)

Menunjukkan bahwa nilai tolerance $>0,1$ dan nilai VIF $<10$ bahwa tidak terjadi korelasi antar variabel bebas.

\section{Uji Heteroskedastisitas}

Beberapa cara untuk mendeteksi ada atau tidaknya heteroskedastisitas:

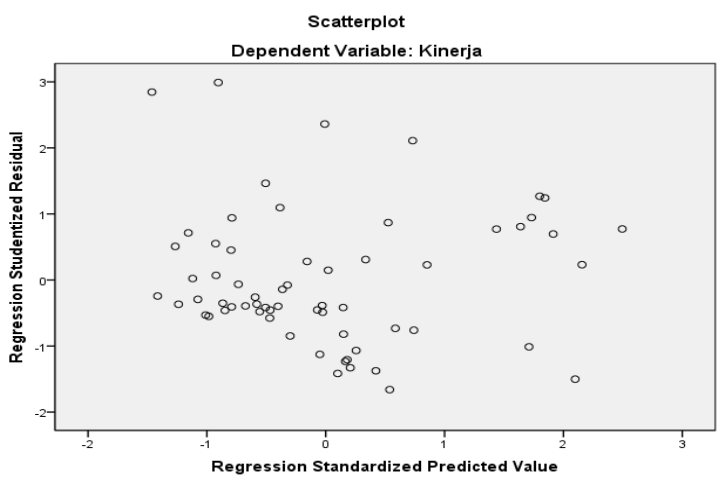

Gambar 3. Uji Heteroskedastisitas

Sumber : Hasil Penelitian, 2020 (Data diolah)

Dari grafiki scatterplot bahwa titik-titik menyebar dengan pola yang tidak jelas baik diatas maupun dibawah angka nol (0) pada sumbu Y, tidak berkumpul di satu tempat, sehingga dari grafik scatterplot dapat disimpulkan bahwa tidak terjadi heteroskedastisitas pada model regresi.

Tabel 4. Uji Gletjer Coefficients $^{\mathrm{a}}$

\begin{tabular}{|c|c|c|c|c|c|c|}
\hline \multirow{2}{*}{\multicolumn{2}{|c|}{ Model }} & \multicolumn{2}{|c|}{ Unstandardized Coefficients } & \multirow{2}{*}{$\begin{array}{l}\text { Standardized } \\
\text { Coefficients } \\
\text { Beta } \\
\end{array}$} & \multirow[b]{2}{*}{$\mathrm{t}$} & \multirow[b]{2}{*}{ Sig. } \\
\hline & & $\mathrm{B}$ & Std. Error & & & \\
\hline \multirow[t]{4}{*}{1} & (Constant) & 4.575 & 2.743 & & 1.667 & .101 \\
\hline & Disiplin & .064 & .064 & .135 & 998 & .322 \\
\hline & Pelatihan & .073 & .077 & .130 & .950 & .346 \\
\hline & Kepuasan & -.021 & .075 & -.038 & -.278 & .782 \\
\hline
\end{tabular}

a. DependentVariable:ABSUT

Sumber : Hasil Penelitian, 2020 (Data diolah) 
Nilai signifikan dari variable bebas $>0,05$ bahwa tidak terjadi masalah heteroskedastisitas.

\section{Model Penelitian}

Pengujian hipotesis yang digunakan dalam penelitian adalah dengan menggunakan analisis regresi linier berganda. Rumus persamaan regresi linier berganda adalah sebagai berikut :

$$
\mathrm{Y}=\mathrm{a}+\mathrm{b}_{1} \mathrm{X}_{1}+\mathrm{b}_{2} \mathrm{X}_{2}+\mathrm{b}_{3} \mathrm{X}_{3}+\mathrm{e}
$$

Model regresi yang digunakan adalah sebagai berikut :

Tabel 5. Hasil Analisis Regresi Linear Berganda

\begin{tabular}{|c|c|c|c|c|c|c|}
\hline \multirow{3}{*}{\multicolumn{2}{|c|}{ Model }} & \multirow{2}{*}{\multicolumn{2}{|c|}{ Unstandardized Coefficients }} & & \multirow[b]{3}{*}{$\mathrm{t}$} & \multirow[b]{3}{*}{ Sig. } \\
\hline & & & & Coefficients & & \\
\hline & & $B$ & Std. Error & Beta & & \\
\hline \multirow[t]{4}{*}{1} & (Constant) & .011 & 4.485 & & .002 & .998 \\
\hline & Disiplin & .215 & .105 & 229 & 2.056 & .044 \\
\hline & Pelatihan & .309 & .126 & 278 & 2.457 & .017 \\
\hline & Kepuasan & 320 & .122 & 299 & 2.624 & .011 \\
\hline
\end{tabular}

Sumber : Hasil Penelitian, 2020 (Data diolah)

\section{Prestasi Kerja Karyawan $=$ 0,111 + 0,215 Disiplin +0,309 Pelatihan + 0,320 Kepuasan Kerja}

Penjelasan regresi linier berganda diatas adalah :

Apabila variable bebas disiplin kerja, pelatihan dan kepuasan kerja tidak ada atau konstan maka variable terikat prestasi kerja karyawan pada sebesar 0,011 satuan. Apabila setiap kenaikan variabel bebas disiplin kerja 1 satuan akan meningkatkan variabel terikat prestasi kerja karyawan sebesar 0,215 satuan dengan anggapan variabel lainnya tetap. Apabila setiap kenaikan variabel bebas pelatihan 1 satuan akan meningkatkan variabel terikat prestasi kerja karyawan sebesar 0,309 satuan dengan anggapan variabel lainnya tetap. Apabila setiap kenaikan variabel bebas kepuasan kerja 1 satuan akan meningkatkan variabel terikat prestasi kerja karyawan sebesar 0,320 satuan dengan anggapan variabel lainnya tetap. 


\section{Koefisien Determinasi Hipotesis}

Hasil pengujian determinasi yaitu :

Tabel 6. Uji Koefisien Determinasi

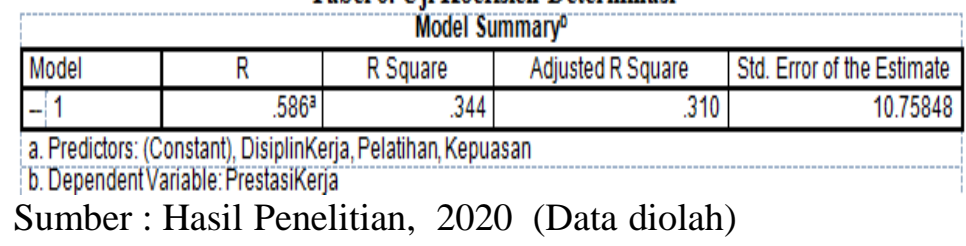

Nilai sebesar 0,310 atau 31\% dari variasi prestasi kerja karyawan PT Angkasa Tour Medan yang dapat dijelaskan oleh variasi variabel bebas yaitu bebas Disiplin kerja, pelatihan kerja dan kepuasan kerja sedangkan sisanya sebesar 69\% (100\% - 31\%) dijelaskan oleh variabel lain yang tidak diteliti pada penelitian ini, seperti pengembangan karir, promosi jabatan, motivasi kerja dan sebagainya.

\section{Pengujian Hipotesis Secara Simultan (Uji F)}

Hasil pengujian hipotesis simultan yaitu :

Tabel 7. Uji Simultan (Uji F)

\begin{tabular}{|l|r|r|r|r|r|r|}
\hline \multicolumn{2}{|l|}{ Model } & Sum of Squares & \multicolumn{1}{|c|}{ Af } & Mean Square & F & Sig. \\
\hline 1 & Regression & 3573.468 & 3 & 1191.156 & 10.291 & $.000^{3}$ \\
& Residual & 6828.945 & 59 & 115.745 & & \\
& Total & 10402.413 & 62 & & & \\
\hline
\end{tabular}

Sumber : Hasil Penelitian, 2020 (Data diolah)

Nilai $F_{\text {hitung }}(10,291)>F_{\text {tabel }}(3,14)$ dan $0,000<0,05$, berarti bahwa secara simultan Disiplin kerja, pelatihan kerja dan kepuasan kerja berpengaruh positif dan signifikan terhadap prestasi kerja karyawan PT Angkasa Tour Medan.

\section{Pengujian Hipotesis Secara Parsial (Uji t)}

Hasil pengujian hipotesis parsial yaitu:

Tabel 8. Uji Parsial (Uji t)

\begin{tabular}{|c|c|c|c|c|c|c|}
\hline \multirow{2}{*}{\multicolumn{2}{|c|}{ Model }} & \multicolumn{2}{|c|}{ Unstandardized Coefficients } & \multirow{2}{*}{$\begin{array}{c}\begin{array}{c}\text { Standardized } \\
\text { Coefficients }\end{array} \\
\text { Beta }\end{array}$} & \multirow[b]{2}{*}{$\mathrm{t}$} & \multirow[b]{2}{*}{ Sig. } \\
\hline & & $\mathrm{B}$ & Std. Error & & & \\
\hline \multirow[t]{4}{*}{1} & (Constant) & .011 & 4.485 & & .002 & .998 \\
\hline & Disiplin & .215 & .105 & .229 & 2.056 & .044 \\
\hline & Pelatihan & .309 & .126 & 278 & 2.457 & .017 \\
\hline & Kepuasan & .320 & .122 & .299 & 2.624 & .011 \\
\hline
\end{tabular}

Sumber : Hasil Penelitian, 2020 (Data diolah) 
Nilai $t_{\text {hitung }}>t_{\text {tabel }}$ atau 2,056>2,000 dan $0,044<0,05$ berarti bahwa secara parsial disiplin kerja berpengaruh positif dan signifikan terhadap prestasi kerja karyawan PT Angkasa Tour Medan.

Nilai $t_{\text {hitung }}>t_{\text {tabel }}$ atau 2,457>2,000 dan $0,017<0,05$ berarti bahwa secara parsial pelatihan kerja berpengaruh positif dan signifikan terhadap prestasi kerja karyawan PT Angkasa Tour Medan.

Nilai $t_{\text {hitung }}>t_{\text {tabel }}$ atau 2,624>2,000 dan $0,011<0,05$ berarti bahwa secara parsial kepuasan kerja berpengaruh positif dan signifikan terhadap prestasi kerja karyawan PT Angkasa Tour Medan

\section{Pembahasan}

Nilai $t_{\text {hitung }}>t_{\text {tabel }}$ atau 2,056>2,000 dan 0,044<0,05, berarti bahwa secara parsial disiplin kerja berpengaruh positif dan signifikan terhadap prestasi kerja karyawan PT Angkasa Tour Medan. Menurut Sutrisno (2013:177) masalah diisplin para karyawan yang ada di daam organisasi baik atasan maupn bawahan akan memberi corak terhadap kinerja organisasi. Kinerja organiasi akan tercapai apabila prestasi kerja karyawan ditingkatkan. Disiplin kerja yang dimiliki oleh karyawan sangat penting bagi suatu perusahaan dalam rangka mewujudkan tujuan perusahaan. Tanpa disiplin kerja karyawan yang baik sulit bagi suatu perusahaan mencapai hasil yang optimal. Disiplin kerja karyawan pada perusahaan PT Angkasa Tour Medan masih rendah tercermin dari terjadinya keterlambatan karyawan dan ketidakahdiran karyawan yang masih tinggi serta banyak karyawan yang tidak mematuhi aturan perusahaan.

Nilai $t_{\text {hitung }}>t_{\text {tabel }}$ atau 2,457>2,000 dan $0,017<0,05$, berarti bahwa secara parsial pelatihan kerja berpengaruh positif dan signifikan terhadap prestasi kerja karyawan PT Angkasa Tour Medan. Kasmir (2016:134), dengan mengikuti pelatihan, maka kemampuan dan keterampilannya meningkat, sehingga kinerjanya juga diharapkan meningkat serta dapat mencapai prestasi kerja. Pelatihan kerja berperan penting dalam peningkatan prestasi kerja karyawan. Pelatihan kerja yang diterapkan dalam perusahaan ini masih belum optimal dan efektif sehingga masih belum berdampak pada peningkatan prestasi kerja karyawan. Bahan pelatihan yang diberikan masih sulit untuk mendukung tugas karyawan serta pelatih hanya dari senior atau karyawan yang mempunyai masa kerja yang cukup lama sehingga kurang optimal dalam pemberian pembelajaran kepada karyawan.

Nilai $t_{\text {hitung }}>t_{\text {tabel }}$ atau 2,624>2,000 dan $0,011<0,05$, berarti bahwa secara parsial kepuasan kerja berpengaruh positif dan signifikan terhadap prestasi kerja karyawan PT Ang- 
kasa Tour Medan. Bangun (2012:11), ketika karyawan menilai suatu pekerjaan menyenangkan untuk dikerjakan, mereka mengatakan bahwa pekerjaan itu memberikan kepuasan kerja. Keadaan ini dapat dilihat dari hasil pekerjaannya, kepuasan kerja akan dapat meningkatkan kinerja mereka. Kepuasan kerja adalah tingkat kesenangan yang dirasakan seseorang atas peranan atau pekerjaannya dalam organisasi. Tingkat rasa puas individu bahwa mereka mendapat imbalan yang setimpal dari bermacam-macam aspek situasi pekerjaan dari organisasi tempat mereka bekerja. Kepuasan kerja karyawan masih rendah terlihat dari seringnya karyawan tidak optimal dalam bekerja.

\section{KESIMPULAN DAN SARAN}

\section{Kesimpulan}

Kesimpulan dari hasil penelitian ini adalah sebagai berikut :

1. Nilai $t_{\text {hitung }}>t_{\text {tabel }}$ atau 2,056>2,000 dan 0,044<0,05, berarti bahwa secara parsial disiplin kerja berpengaruh positif dan signifikan terhadap prestasi kerja karyawan PT Angkasa Tour Medan.

2. Nilai $t_{\text {hitung }}>t_{\text {tabel }}$ atau $2,457>2,000$ dan $0,017<0,05$, berarti bahwa secara parsial pelatihan kerja berpengaruh positif dan signifikan terhadap prestasi kerja karyawan PT Angkasa Tour Medan.

3. Nilai $t_{\text {hitung }}>t_{\text {tabel }}$ atau $2,624>2,000$ dan $0,011<0,05$, berarti bahwa secara parsial kepuasan kerja berpengaruh positif dan signifikan terhadap prestasi kerja karyawan PT Angkasa Tour Medan

4. Nilai $F_{\text {hitung }}(10,291)>F_{\text {tabel }}(3,14)$ dan $0,000<0,05$, berarti bahwa secara simultan Disiplin kerja, pelatihan kerja dan kepuasan kerja berpengaruh positif dan signifikan terhadap prestasi kerja karyawan PT Angkasa Tour Medan.

\section{Saran}

Saran-saran yang berguna bagi penelitian ini adalah :

1. Bagi peneliti, diharapkan dapat mempraktekkan hasil penelitian di perusahaan tempat peneliti bekerja.

2. Bagi Universitas Prima Indonesia, disarankan agar dapat mempublikasikan hasil penelitian ini yang nantinya dapat dijadikan sebagai bahan acuan bagi peneliti selanjutnya 
3. Bagi Perusahaan, prestasi kerja karyawan secara keseluruhan sangat dipengaruhi oleh disiplin kerja, pelatihan kerja dan kepuasan kerja. Peningkatan kedua variabel tersebut baik secara parsial maupun bersama-sama dapat meningkatkan prestasi kerja karsecara maksimal. Maka disarankan agar perusahaan dapat meningkatkan dan memperbaiki kedua variabel tersebut di dalam perusahaan

4. Bagi peneliti selanjutnya, disarankan untuk menambah variabel lain di luar dari variabel yang diteliti oleh peneliti.

\section{DAFTAR PUSTAKA}

Bangun, Wilson. 2012. Manajemen Sumber Daya Manusia. Jakarta : PT. Gelora Aksara Pratama.

Edison, Emron, Yohny Anwar dan Imas Komariyah. 2016. Manajemen Sumber Daya Manusia. Bandung : Alfabeta.

Fahmi, Irfan. 2016. Konsep-konsep Dasar Manajemen Personalia. Bandung : Refika Aditama.

Hasibuan, S,P, Malayu. 2013. Manajemen Sumber Daya Manusia. Jakarta : Bumi Aksara.

Kasmir. 2016. Manajemen Sumber Daya Manusia. Edisi Pertama. Jakarta : Prenadamedia Group.

Malikhatun, Waskito, J., \& Dwita, A. (2020). Pengaruh Daya Tarik Wisata, Kuliner Wisata, dan Kepuasan Wisatawan terhadap Niat Kunjung Kembali pada Obyek Wisata Pasar Slumpring Desa Cempaka Kecamatan Bumijawa Kabupaten Tegal. Permana : Jurnal Perpajakan, Manajemen, Dan Akuntansi, 12(1), 67-73. https://doi.org/10.24905/permana.v12i1.95

Mangkunegara, Prabu, Anwar, A, A. 2013. Manajemen Sumber Daya Manusia Perusahaan. Bandung : Remaja Rosdakarya

Priansa, Juni Donni. 2016. Perencanaan dan Pengembangan Sumber Daya Manusia. Bandung : Alfabeta.

Solekhah, N., \& Dhani, B. A. (2017). Analisis Pengaruh Kualitas Produk dan Kualitas Pelayanan terhadap Kepuasan Masyarakat dalam Pengurusan Kartu Tanda Penduduk Elektronik (KTP-EL) di Kecamatan Randudongkal Kabupaten Pemalang. Permana : Jurnal Perpajakan, Manajemen, Dan Akuntansi, 9(1), 112123. Retrieved from https://permana.upstegal.ac.id/index.php/permana/article/view/143

Sutrino, Edy. 2013. Budaya Organisasi. Jakarta : Bumi Aksara. . 2016. Manajemen Sumber Daya Manusia. Jakarta : Bumi Aksara.

Tegar. 2019. Manajemen Sumber Daya Manusia. Bandung: Alfabeta 